\title{
Effects of green tea catechins on the pro-inflammatory response after haemorrhage/resuscitation in rats
}

\author{
Borna Relja $^{1 *}$, Eva Töttel ${ }^{1}$, Lara Breig ${ }^{1}$, Dirk Henrich ${ }^{1}$, Heinz Schneider ${ }^{2}$, Ingo Marzi ${ }^{1}$ and Mark Lehnert ${ }^{1}$ \\ ${ }^{1}$ Department of Trauma, Hand and Reconstructive Surgery, Hospitals of the Johann Wolfgang Goethe-University, Frankfurt \\ am Main, 60590 Frankfurt, Germany \\ ${ }^{2}$ HealthEcon AG, Steinentorstrasse 19, CH-4051 Basle, Switzerland
}

(Received 21 April 2010 - Revised 23 August 2010 - Accepted 18 November 2010 - First published online 4 February 2011)

\section{Abstract}

Plant polyphenols, i.e. green tea extract (GTE), possess high antioxidative and anti-inflammatory capacity, thus being protective in various models of acute inflammation. However, their anti-inflammatory effect and a feasible mechanism in haemorrhage/resuscitation $(\mathrm{H} / \mathrm{R})$-induced liver injury remain unknown. We investigated the effects of GTE and the role of NF- $\mathrm{B}$ in the pathogenesis of liver injury induced by $\mathrm{H} / \mathrm{R}$, and their effects on intercellular adhesion molecule-1 (ICAM-1) expression and neutrophil infiltration. Female Lewis rats were fed a standard chow diet (control, ctrl) or a diet containing $0 \cdot 1 \%$ polyphenolic GTE for five consecutive days before $\mathrm{H} / \mathrm{R}$. Rats were haemorrhaged to a mean arterial pressure of 30 (SEM 2) $\mathrm{mmHg}$ for $60 \mathrm{~min}$ and resuscitated. Control groups (sham_ctrl and sham_GTE) underwent surgical procedures without H/R. At $2 \mathrm{~h}$ after resuscitation, tissues were harvested. Serum alanine aminotransferase (ALT) and IL-6 were measured. Hepatic necrosis, ICAM-1 expression and polymorphonuclear leucocyte (PMNL) infiltration were assessed. Hepatic expression of IкB $\alpha$ (phospho) was measured. H/R induced strong liver damage with increased necrosis and serum ALT levels. Compared with both sham groups, inflammatory markers (serum IL- 6 and hepatic PMNL infiltration) were elevated after $\mathrm{H} / \mathrm{R}(P<0 \cdot 05)$. Also, H/R increased IкB $\alpha$ phosphorylation. GTE administration markedly $(P<0 \cdot 05)$ decreased serum ALT and IL-6 levels, hepatic necrosis as well as PMNL infiltration and the expression of ICAM-1 and phosphorylated IкB $\alpha$ compared with $\mathrm{H} / \mathrm{R}$. In conclusion, we observed that NF- $\mathrm{BB}$ activation plays an important role in the pathogenesis of liver injury after $\mathrm{H} / \mathrm{R}$ through the up-regulation of hepatic ICAM-1 expression and subsequent PMNL infiltration. GTE pre-treatment prevents liver damage in this model of acute inflammation through a NF-кB-dependent mechanism.

Key words: Plant polyphenols: Green tea extract: NF-אB: Haemorrhagic shock: Liver: Inflammation: In vivo studies

Trauma has become one of the leading causes of global mortality (10\%), whereas blood loss remains the major contributor to mortality after trauma ${ }^{(1,2)}$. Systemic and local effects of resuscitated blood loss frequently include the systemic inflammatory response syndrome that may lead to the development of dysfunction or even failure of multiple organs ${ }^{(3,4)}$. Systemic hypotension (low-flow hypoxia) followed by resuscitation compromises the integrity of several organs at the level of the microcirculation, an effect that is mediated - at least in part - via the activation of monocytes and polymorphonuclear leucocytes (PMNL) with subsequent release of inflammatory cytokines. In the clinical setting, a high activation state of PMNL is associated with the systemic inflammatory response syndrome ${ }^{(5,6)}$. Haemorrhage/resuscitation (H/R)induced pre-activation or 'priming' of PMNL is an essential step for neutrophils to enhance their functional responses to pro-inflammatory cytokines and reactive oxygen species ${ }^{(6,7)}$.
Liver injury is associated with an increased PMNL accumulation in the liver following $\mathrm{H} / \mathrm{R}^{(8,9)}$. Furthermore, $\mathrm{H} / \mathrm{R}$ increases the expression of endothelial adhesion molecules, such as intercellular adhesion molecule-1 (ICAM-1) in the liver ${ }^{(10)}$. Moreover, hepatic and serum IL-6 levels were elevated after $\mathrm{H} / \mathrm{R}^{(9)}$. IL-6-deficient mice did not show enhanced PMNL infiltration into the liver, increased hepatic necrosis and organ damage as opposed to wild-type mice following $\mathrm{H} / \mathrm{R}^{(11)}$. NF- $\kappa \mathrm{B}$ was activated in the liver following $\mathrm{H} / \mathrm{R}^{(11)}$. Previous studies have shown that NF- $\kappa \mathrm{B}$ activation up-regulated the gene expression of pro-inflammatory mediators that are associated with PMNL infiltration in the liver after $\mathrm{H} / \mathrm{R}$. These pro-inflammatory mediators include ICAM-1 and IL- $6^{(12,13)}$. Activation and regulation of NF- $\kappa \mathrm{B}$ are controlled by $\mathrm{I} \kappa \mathrm{B}$ proteins, which mask the nuclear localisation signal of NF- $\mathrm{KB}$, thereby inhibiting its nuclear translocation ${ }^{(14)}$. Phosphorylation of inhibitor $\kappa \mathrm{B} \alpha(\mathrm{I} \kappa \mathrm{B} \alpha)$ at its regulatory

Abbreviations: EGCG, epigallocatechin gallate; GTE, green tea extract; H/R, haemorrhage/resuscitation; ICAM-1, intercellular adhesion molecule-1; I/R, ischaemia/reperfusion; PMNL, polymorphonuclear leucocyte; RT, room temperature.

*Corresponding author: Dr B. Relja, fax + 496963017108 , email info@bornarelja.com 
N-terminus on serine 32 and 36 leads to subsequent conjugation with ubiquitin, and thereby degradation of the inhibitory unit with the following activation of the transcription factor NF- $\kappa \mathrm{B}^{(14)}$.

Green tea (Camellia sinensis) extracts (GTE) contain high levels of polyphenols consisting mostly of catechin and catechin gallates including epicatechin, gallocatechin, epigallocatechin, epicatechin gallate and epigallocatechin gallate (EGCG) that are efficient free radical and singlet oxygen scavengers ${ }^{(15-18)}$. GTE reduced hepatic ischaemia/reperfusion (I/R)-induced injury in various in vivo models of acute inflammation $^{(19-21)}$. Hepatoprotective effects of GTE after $\mathrm{I} / \mathrm{R}$ were attributed to its antioxidative and anti-inflammatory properties $^{(19,21)}$. A recent study has reported that green tea consumption is associated with a reduced risk of total stroke incidence, cerebral infarction and cerebral haemorrhage in humans ${ }^{(22)}$. However, the effects of green tea in $\mathrm{H} / \mathrm{R}$-induced liver injury as well as the underlying mechanism have not been studied yet. The objective of the present study was to evaluate the effects of GTE and the role of NF- $\kappa$ B in the pathogenesis of liver injury induced by $\mathrm{H} / \mathrm{R}$, and their effects on PMNL infiltration and ICAM-1 expression.

\section{Materials and methods}

\section{Animals and experimental model}

Female Lewis rats ( $n$ 24) weighing 180-250g were obtained from Harlan (Borchen, Germany). At $5 \mathrm{~d}$ before $\mathrm{H} / \mathrm{R}$, rats received daily a diet containing $0 \cdot 1 \%$ polyphenolic extracts from $C$. sinensis (GTE; Sunphenon 90LB (low bitter), $>80 \%$ polyphenols and $>80 \%$ catechins, which contain $>40 \%$ EGCG, kindly provided by H. S.) or a regular chow diet (control, ctrl). After an overnight fast, rats were anaesthetised with isofluran (1.5\%), and the right carotid artery, the right femoral artery and the left jugular vein were cannulated with polyethylene tubing. Then, shock was induced over $5 \mathrm{~min}$ by withdrawing blood from the right carotid artery into a heparinised syringe $(0.02 \mathrm{mg})$ to a mean blood pressure of $30-32 \mathrm{mmHg}$. Systemic blood pressure was monitored in the right femoral artery using a blood pressure analyser (BPA 400; Digi-Med, Louisville, KY, USA). Constant pressure was maintained by further withdrawal of small volumes of blood as necessary for $60 \mathrm{~min}$. Then, rats were resuscitated by transfusion of $60 \%$ of the shed blood and twice the shed blood volume as Ringer's lactate solution with a syringe pump over $30 \mathrm{~min}$ via the left jugular vein. After the end of resuscitation, the catheters were removed, the vessels were occluded and the wounds were closed. At $2 \mathrm{~h}$ after the end of resuscitation, the animals were re-anaesthetised. The cava was punctured, blood was collected and tissue was harvested. The liver was flushed with normal saline, infused and fixed with $10 \%$ buffered formalin through the portal vein, embedded in paraffin and subsequently sectioned and stained with haematoxylin-eosin. Sham-operated animals underwent the same surgical procedures, but haemorrhage was not carried out (sham_ctrl and sham_GTE, six animals per group). Body temperature was measured in the colon and maintained at $37^{\circ} \mathrm{C}$ throughout the experiment with a heating pad. Animal protocols were approved by the Veterinary Department of the Regional Council in Darmstadt, Germany.

\section{Examination of tissue injury}

Sera were stored at $-80^{\circ} \mathrm{C}$ for later analysis of alanine aminotransferase using the Vitros 250 device (Ortho-Clinical Diagnostics, Neckargemünd, Germany). Determination of the histological damage was performed by an independent examiner who allocated the haematoxylin-eosin-stained liver sections to various experimental groups in a blinded manner as published previously ${ }^{(23)}$.

\section{Detection of polymorphonuclear leucocytes}

Analysis of the hepatic infiltration with PMNL was performed by chloroacetate esterase staining ( $4 \%$ pararosanilin, $4 \%$ sodium nitrite and naphthol solution) for $30 \mathrm{~min}$ at room temperature (RT). Sections were counterstained with haematoxylin. PMNL infiltration was determined by counting the number of chloroacetate esterase-positive cells in a total of twenty-five high-power $(400 \times)$ fields/liver section per rat in a blinded manner as described previously ${ }^{(24)}$. Data from each tissue section were pooled to determine mean values.

\section{Quantification of cytokine levels}

Concentrations of serum IL-6 were determined using a Quantikine Rat IL-6 ELISA kit of R\&D Systems according to the manufacturer's instructions (Wiesbaden-Nordenstadt, Germany). ELISA ninety-six-well microtitre plates were analysed using a microplate reader (Bio-Tek Ceres UV900C; Bio-Tek, Winooski, VT, USA).

\section{Western blotting}

Liver tissue was homogenised in lysis buffer at $4^{\circ} \mathrm{C}$, followed by centrifugation for $30 \mathrm{~min}$ at $4^{\circ} \mathrm{C}$ at $20000 \mathrm{~g}$. Supernatants were stored at $-80^{\circ} \mathrm{C}$ for later analysis. Lysates $(50 \mu \mathrm{g}$ protein) were separated by electrophoresis on $12 \%$ polyacrylamide SDS gels and transferred to nitrocellulose membranes (Amersham-Buchler, Braunschweig, Germany). ІкB $\alpha$ (phospho) was detected using a rabbit polyclonal IKB- $\alpha$ (phospho $\mathrm{S} 32+\mathrm{S} 36$ ) antibody (Abcam, Cambridge, UK). $\beta$-Actin, which served as a loading control, was determined using an anti$\beta$-actin antibody (Sigma, Taufkirchen, Germany). Blots were blocked (10\% non-fat dry milk in $1 \mathrm{~mm}$-Tris, $150 \mathrm{~mm}-\mathrm{NaCl}$, $\mathrm{pH} 7.4$ ) for $1 \mathrm{~h}$, incubated $1 \mathrm{~h}$ at RT with primary antibody (diluted according to the manufacturer's instructions in blocking buffer with $0.5 \%$ Tween 20 and $0.5 \%$ bovine serum albumin) and then incubated for $1 \mathrm{~h}$ with a horseradish peroxidase-conjugated secondary antibody (Santa Cruz Biotechnology, Santa Cruz, CA, USA) diluted 1:1000 in blocking buffer with $0.5 \%$ Tween 20 and $0.5 \%$ bovine serum albumin at RT. Proteins were detected with $\mathrm{ECL}^{\mathrm{TM}}$ Western blot detection reagents (GE Healthcare, Munich, Germany). Films were digitised, and the integrated density of individual bands was 
determined using MultiAnalyst software (Bio-Rad, Munich, Germany). The amount of protein expression was normalised to $\beta$-actin by densitometric measurements using the same software.

\section{Staining of intercellular adhesion molecule-1}

Cryosectioned liver samples $(5 \mu \mathrm{m})$ were air-dried overnight, fixed in acetone for $10 \mathrm{~min}$ at RT and air-dried for $60 \mathrm{~min}$ at RT. Sections were washed with PBS and water. Then, endogenous peroxidase activity was blocked with $\mathrm{H}_{2} \mathrm{O}_{2}$ (for 10 min, RT, ready-to-use solution; Labvision, Fremont, CA, USA). Liver sections were washed and incubated with blocking solution ( $2 \%$ bovine serum albumin in PBS) for $1 \mathrm{~h}$ at RT. Mouse anti-rat CD54 monoclonal antibody (BD Pharmingen, Heidelberg, Germany) diluted 1:150 in antibody dilution buffer (AB Dilution Buffer; Dako, Hamburg, Germany) containing $1 \%$ bovine serum albumin was used as the primary antibody (overnight incubation, $4^{\circ} \mathrm{C}$ ). Anti-mouse horseradish peroxidase-linked secondary antibody (30 min, RT, Histofine; Nichirei Biosciences, Tokyo, Japan) and diaminobenzidine (Labvision, Fremont, CA, USA) were used to detect specific binding. Sections were counterstained with haematoxylin. The immunostained tissue sections were captured at $400 \times$ and analysed in a blinded manner. The extent of labelling in the liver lobule was defined as the percentage of the field area within a preset colour range determined by the software (Adobe Photoshop 7.0; Adobe Systems Inc., San Jose, CA, USA). Data from each tissue section (ten fields/section) were pooled to determine mean values.

\section{Statistical analysis}

Differences between groups were determined by one-way ANOVA using a multiple comparison procedure (StudentNewman-Keuls) and by ANOVA on ranks as appropriate. A $P$ value of $<0.05$ was considered significant. Data are expressed as means with their standard errors.

\section{Results}

\section{Cell damage after haemorrhage and resuscitation in the} liver

Serum alanine aminotransferase as a marker of hepatocellular damage increased to 1385 (SEM 191) IU/l at $2 \mathrm{~h}$ after H/R compared with 97 (SEM 14) IU/1 after the sham operation $(P<0.001 ;$ Fig. 1(e)). In GTE pre-treated animals, alanine aminotransferase release decreased by $72 \%$ after $\mathrm{H} / \mathrm{R}(385$ (sEm 63) IU/1, $P<0.01$; Fig. 1(e)) compared with the control group after H/R. GTE did not affect alanine aminotransferase levels after the sham operation compared with the sham_ctrl group (Fig. 1(e)).

\section{Histopathological changes in liver tissue after haemorrhage and resuscitation}

Evaluation of hepatic necrosis at $2 \mathrm{~h}$ after $\mathrm{H} / \mathrm{R}$ in histological sections showed confluent, large areas of coagulative necrosis as indicated by cellular enlargement and dissolution in the H/R_ctrl group (Fig. 1 $(\mathrm{a}-\mathrm{c})$ ). Tissue damage occurred predominantly in the pericentral areas of liver sections. These changes were detected neither in control sham-operated nor in GTE pre-treated sham-operated rats, respectively (Fig. 1(a-c)). GTE chow substantially decreased hepatic necrosis after H/R (Fig. 1(d)) compared with vehicle-treated rats (Fig. 1(c)).

\section{Systemic pro-inflammatory changes after haemorrhage and resuscitation - serum IL-6 levels}

The systemic immune response, a common sequela after resuscitated blood loss, was determined by serum IL-6 levels. Compared with the sham_ctrl group (15 (sEm 12) pg/ml), serum IL-6 levels increased in the vehicle-treated group after $\mathrm{H} / \mathrm{R}(1641$ (sem 535) pg/ml, $P<0.05$; Fig. 2). This increase after H/R was prevented by GTE chow (420 (sEM 124) pg/ml,
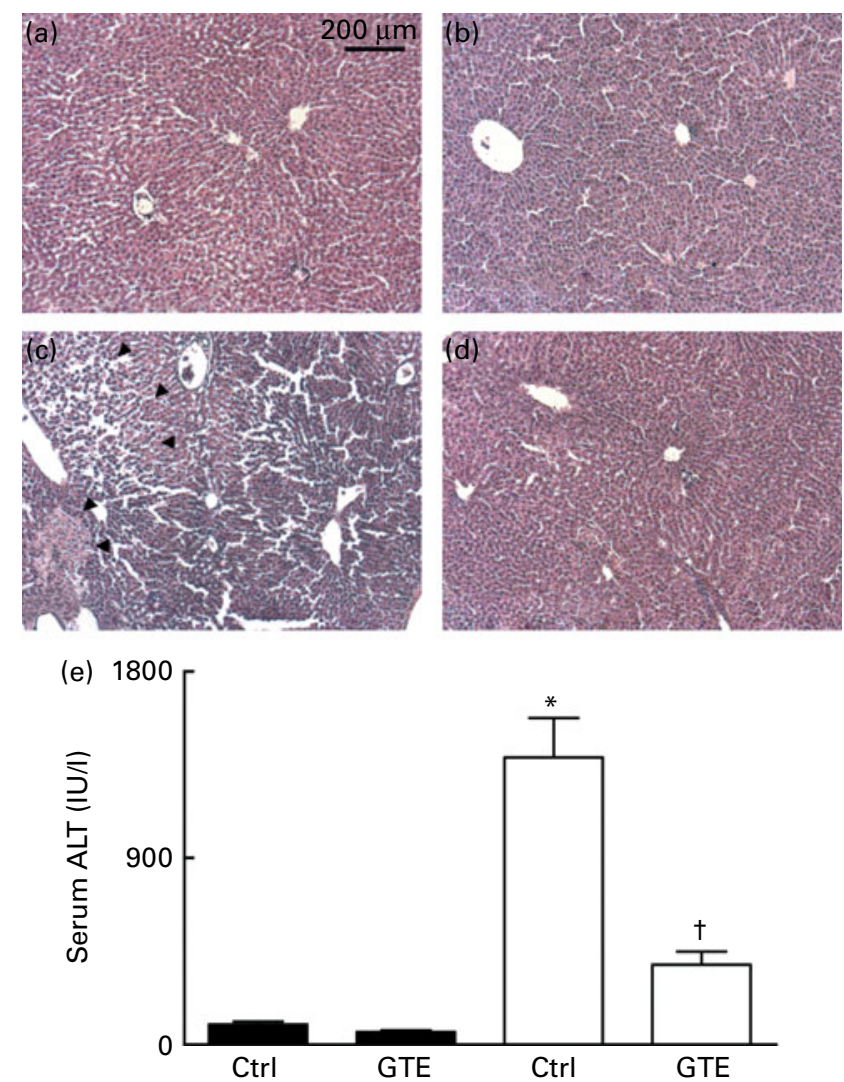

Fig. 1. Green tea extract (GTE) reduces histological liver necrosis and serum alanine transaminase (ALT) levels at $2 \mathrm{~h}$ after resuscitation. At $5 \mathrm{~d}$ before haemorrhagic shock and resuscitation $(H / R)$, rats received chow containing GTE $(0.1 \%$, haemorrhage/resuscitation (H/R)_GTE) or regular chow (H/R_ctrl (control)). Sham-operated ( $(\mathbf{D})$ animals underwent the same surgical procedures, but $H / R(\square)$ was not carried out (sham_GTE and sham_ctrl, respectively). Representative haematoxylin and eosin-stained liver lobes from vehicle-treated ((a) after sham operation and (c) after $\mathrm{H} / \mathrm{R}$ ) and GTEtreated ((b) after sham operation and (d) after $H / R$ ) rats are shown. Scale bar is $200 \mu \mathrm{m}$. Blood samples were collected at $2 \mathrm{~h}$ after resuscitation for the measurement of (e) serum ALT. Values are means with standard errors represented by vertical bars (six animals per group). ${ }^{*}$ Mean values were significantly different from those of the sham-operated animals $(P<0.001)$. † Mean values were significantly different from those of the shock control group $(P<0.01)$. 


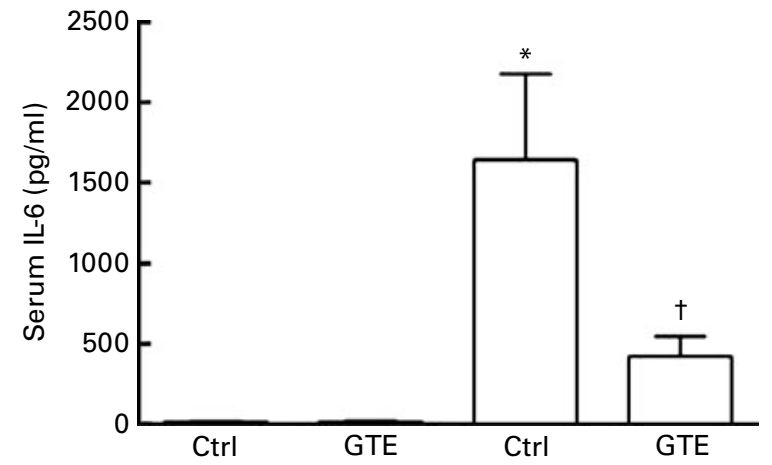

Fig. 2. Green tea extract (GTE) decreases serum IL-6 levels after haemorrhage and resuscitation in rats. Blood samples were collected at $2 \mathrm{~h}$ after resuscitation. Serum concentration of IL-6 was determined by ELISA. Ctrl denotes vehicle treatment, GTE denotes GTE administration. Values are means with standard errors represented by vertical bars (six animals per group). * Mean values were significantly different compared from those of the sham-operated animals $(\square, P<0 \cdot 05)$. $†$ Mean values were significantly different compared from those of the H/R_ctrl group $(\square, n 6, P<0.05)$.

$P<0 \cdot 05$; Fig. 2). After the sham operation, serum IL-6 levels did not differ between the control and GTE groups (15 (SEM 12) and 12 (SEM 9) pg/ml, respectively; Fig. 2). These results indicate that systemic pro-inflammatory changes after $H / R$ were substantially attenuated by GTE pre-treatment.

\section{Local pro-inflammatory changes after haemorrhage and resuscitation - intercellular adhesion molecule expression and hepatic neutrophil accumulation}

The expression of ICAM-1, represented by strong brown staining of endothelial cells in the control group, increased 8.4-fold compared with the sham-operated control rats (76 (SEM 2) and 9 (SEM 2) \%, respectively, $P<0.05$; Fig. 3(a) and (c)). Hepatic ICAM-1 expression was markedly reduced in the group of animals fed with GTE chow (19 (sem 2)\%; Fig. 3(d)).

Hepatic neutrophil infiltration increased to 8 (SEM 1) cells/ high-power field at $2 \mathrm{~h}$ after resuscitation compared with the sham operation (1 (SEM 1) cells/high-power field, $P<0 \cdot 05$; Fig. 3(e)). GTE significantly diminished hepatic neutrophil infiltration after $\mathrm{H} / \mathrm{R}$ (3 (SEM 1) cells/high-power field, $P<0.05$; Fig. 3(e)).

These results indicate that local pro-inflammatory changes after $\mathrm{H} / \mathrm{R}$ were markedly reduced by GTE chow administration.

\section{Western blot analysis of the NF- $\kappa B$ inhibitor I $\kappa B \alpha$ after haemorrhagic shock and resuscitation}

To analyse the mechanism influenced by GTE, detection of phosphorylated I $\mathrm{I} \mathrm{B} \alpha$ was performed by Western blot in liver homogenates collected at $2 \mathrm{~h}$ after resuscitation. Densitometric analysis of protein content related to $\beta$-actin content showed an increase in phosphorylated $\mathrm{I} \kappa \mathrm{B} \alpha$ after $\mathrm{H} / \mathrm{R}$ of 47 (SEM 4)\% compared with 6 (SEM 1)\% in sham-operated rats $(P<0 \cdot 05$, Fig. 4(a) and (b)). GTE administration prevented the increase in the amount of phosphorylated $\mathrm{I} \kappa \mathrm{B} \alpha$ protein compared with vehicle-treated control rats after H/R (12 (sEM
4) $\%, P<0.05$; Fig. 4(a) and (b)). These results indicate that $\mathrm{H} / \mathrm{R}$ induced NF- $\mathrm{B}$ activation, an effect that was strongly inhibited by GTE pre-treatment before $H / R$.

\section{Discussion}

In the present study, haemorrhage followed by resuscitation induced liver injury, the release of pro-inflammatory cytokine IL-6, the enhanced expression of ICAM-1 as well as hepatic infiltration with PMNL (Figs. 1-3). These changes were associated with $\mathrm{I} \kappa \mathrm{B} \alpha$ activation, suggesting that the activation of $\mathrm{NF}-\kappa \mathrm{B}$ is involved in the pathogenesis of liver damage induced by $\mathrm{H} / \mathrm{R}$ (Fig. 4). In addition, administration of GTE with its high content of polyphenols prevents liver injury, the release of systemic pro-inflammatory cytokine IL-6, neutrophil infiltration and ICAM-1 expression after $\mathrm{H} / \mathrm{R}$
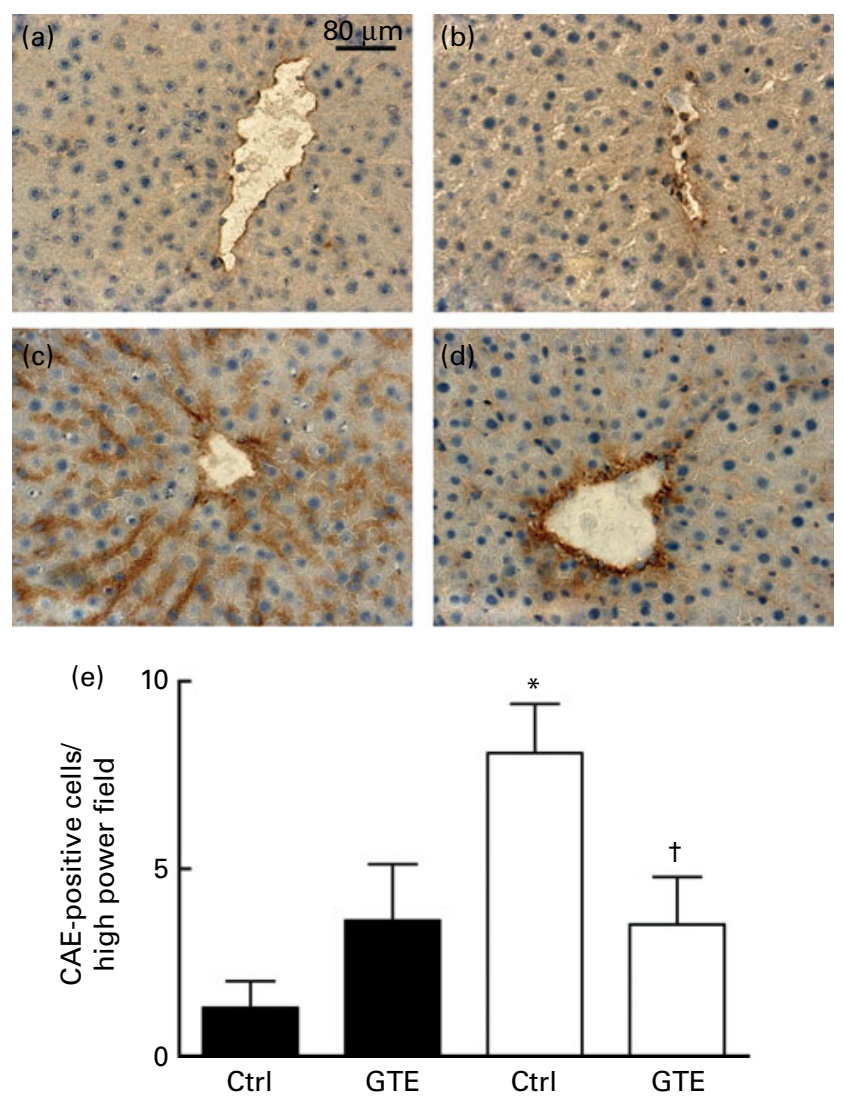

Fig. 3. Green tea extract (GTE) decreases intercellular adhesion molecule-1 (ICAM-1) expression and hepatic neutrophil infiltration after haemorrhage and resuscitation in rats. ICAM-1 (CD54)-stained, representative liver sections from sham-operated rats are shown: (a) regular chow, sham_ctrl (control)) and (b) $0.1 \%$ GTE chow, sham_GTE. ICAM-1-stained, representative liver sections from rats after haemorrhage/resuscitation $(H / R)$ are shown: (c) regular chow, H/R_ctrl and (d) GTE chow, H/R_GTE. Scale bar is $80 \mu \mathrm{m}$. Liver sections were stained for (e) chloroacetate esterase (CAE) cytochemistry. $\square$, Sham; $\square, \mathrm{H} / \mathrm{R}$. Positively stained neutrophils were counted in twentyfive randomly chosen high-power fields (at $400 \times$ ) of each liver specimen and blindly scored for the number of intensely staining CAE-positive PMNL. Ctrl denotes vehicle treatment, GTE denotes GTE administration. Values are means with standard errors represented by vertical bars (six animals per group). *Mean values were significantly different from those of the shamoperated animals $(P<0.05)$. † Mean values were significantly different from those of the H/R_ctrl group ( $n 6, P<0.05)$. 
(a)
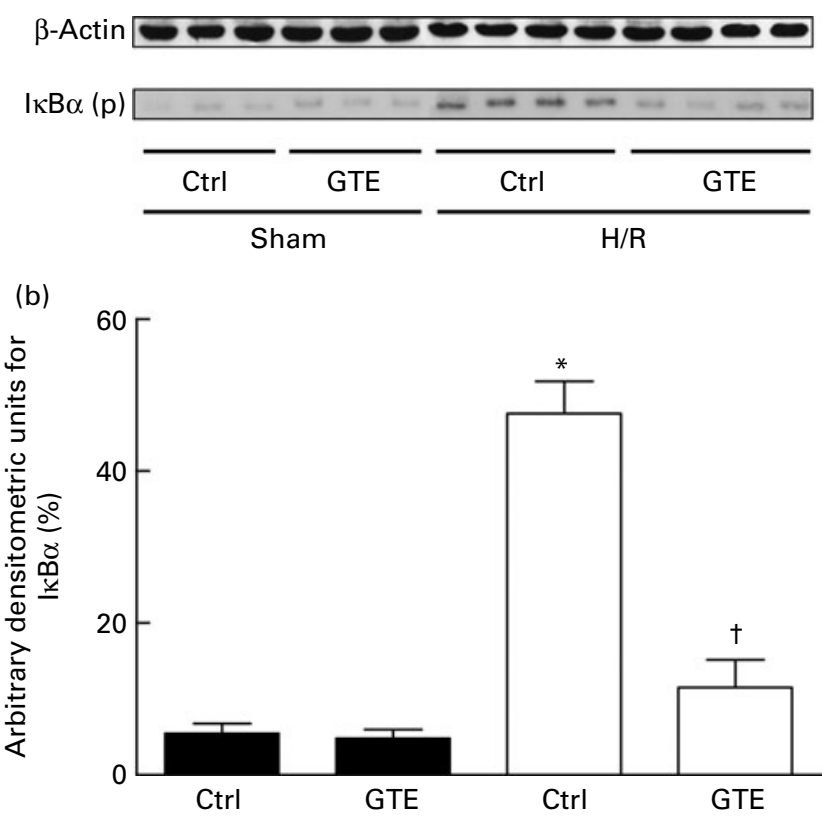

Fig. 4. Green tea extract (GTE) modifies $I_{\kappa} B \alpha$ phosphorylation after haemorrhage and resuscitation. Vehicle (control, ctrl)- or GTE-treated rats were subjected to haemorrhage/resuscitation $(H / R, \square)$ or a sham $(\square)$ operation. At $2 \mathrm{~h}$ after the end of resuscitation, liver tissue was harvested and Western blotting was performed. (a) Lanes 1-6 were liver protein extracts from rats after the sham operation (sham, lanes 1-3: ctrl rats; sham, lanes 4-6: GTEtreated rats) or haemorrhage/resuscitation $(H / R$, lanes 7-10: ctrl rats; $H / R$, lanes 11-14: GTE-treated rats). (b) Densitometric measurements after normalisation to $\beta$-actin staining are plotted. Ctrl denotes vehicle treatment, GTE denotes GTE administration. Values are means with standard errors represented by vertical bars (six animals per group); representative gel from three experiments is shown. ${ }^{*}$ Mean values were significantly different from those of the sham-operated animals $(P<0.05)$, represented by vertical bars. † Mean values were significantly different from those of the ctrl H/R group, represented by vertical bars $(P<0.05, n 6$ (representative gel from three experiments)). І $\mathrm{kB} \alpha(\mathrm{p}), \mathrm{I}_{\kappa} \mathrm{B} \alpha$ (phospho).

(Figs. 1-3). These beneficial, anti-inflammatory effects are associated with decreased $\mathrm{I} \kappa \mathrm{B} \alpha$ activation induced by GTE before $\mathrm{H} / \mathrm{R}$ (Fig. 4). The present study demonstrates the anti-inflammatory and protective role of GTE under conditions of $\mathrm{H} / \mathrm{R}$, suggesting that GTE prevents liver damage in this model of acute inflammation through a NF- $\mathrm{BB}-$ dependent mechanism.

Previous studies have identified numerous mediators such as IL-6, TNF- $\alpha$, ICAM-1, endothelin 1 and haem oxygenase- 1 involved in the pathogenesis of liver damage induced by $\mathrm{H}$ / $\mathrm{R}^{(9,25-27)}$. Most of these mediators are regulated by NF- $\mathrm{B}$. The rapid response transcription factor NF- $\mathrm{KB}$ is maintained in the cytoplasm and consists of p65 and p50 subunits bound to an inhibitory protein $\mathrm{I}_{\kappa} \mathrm{B}^{(14)}$. The phosphorylated I $\mathrm{B}$ is tagged by ubiquitin for subsequent proteolytic degradation that enables the NF- $\kappa \mathrm{B}$ complex to translocate into the nucleus ${ }^{(14)}$. In the nucleus, NF-кB transactivates target genes $^{(28,29)}$. NF- $\mathrm{KB}$ is activated in the lung, heart and liver after haemorrhagic shock followed by resuscitation ${ }^{(30,31)}$. Consistent with these observations, we detected an activation of the NF-кB inhibitory IкB $\alpha$ unit in the liver after $\mathrm{H} / \mathrm{R}$ (Fig. 4). Activated NF- $\mathrm{\kappa B}$ induces the expression of pro-inflammatory mediators, such as IL- $6^{(32)}$. Haemorrhage causes an oxidative stress response that activates hepatic NF- $\mathrm{kB}$ with subsequent IL-6 gene expression ${ }^{(13)}$. These results are further substantiated with the present study, where $\operatorname{I\kappa B} \alpha$ activation was accompanied by enhanced serum IL-6 levels (Figs. 2 and 4). The harmful role of IL- 6 in H/R was demonstrated by IL- 6 knockout mice undergoing $\mathrm{H} / \mathrm{R}$ that were protected from hepatic neutrophil infiltration and liver injury ${ }^{(11)}$. Cell adhesion molecule ICAM-1 is inducible by both NF- $\mathrm{B}$ activation and inflammatory cytokines such as IL-1 $\beta$ and TNF- $\alpha^{(32,33)}$. Expression of ICAM-1 on hepatocytes correlates with the degree of hepatic inflammation ${ }^{(34)}$. Transendothelial migration and the adherence of neutrophils to parenchymal cells require the expression of ICAM-1. Neutrophil infiltration decisively contributes to liver injury in models of $H / R$ and hepatic $\mathrm{I} / \mathrm{R}^{(35)}$. Resistance of ICAM-1-deficient mice to the lethal effects of a high dose of endotoxin correlated with a significant decrease in neutrophil infiltration in the liver ${ }^{(36)}$. In the present study, release of the pro-inflammatory cytokine IL-6 and ICAM-1 up-regulation may lead to an increased adhesion and infiltration with neutrophils into the injured liver, thereby enhancing liver damage after resuscitated blood loss.

In the present study, we used a GTE; Sunphenon 90LB. Major polyphenol species in the extract includes EGCG (>40\%). EGCG posseses the highest reducing potential among catechins. Previous studies have shown that various GTE increase antioxidant capacity in animals and humans under conditions of oxidative stress as demonstrated by electron-spin resonance spectroscopy or detection of oxidative damage to proteins, lipids or $\mathrm{DNA}^{(15-19,21)}$. Frei \& Higdon $^{(17)}$ provided a detailed review of biomarkers for GTE efficiency. Beneficial effects of GTE are most probably due to polyphenols and their ability to scavenge free radical and singlet oxygen ${ }^{(15,16)}$. Catechins administered orally to pregnant rats were also able to penetrate in all fetal organs, whereas EGCG had the highest level of uptake ${ }^{(18)}$. The authors have suggested EGCG as a potential candidate for antioxidant supplementation of the fetus in utero ${ }^{(18)}$ Feeding with a diet supplemented with $0 \cdot 2 \%$ Sunphenon BG (bitter epigallocatechin gallate) $(91.3 \%$ polyphenols and $76.6 \%$ catechins, which contains $9.6 \%$ epigallocatechin, 45.9\% EGCG, 5.3\% epicatechin, $8.6 \%$ epicatechin gallate and others) enhanced aflatoxin $\mathrm{B}_{1}$ detoxification ${ }^{(37)}$. The protective effect of another GTE, Sunphenon (2.9\% catechins, 16.5\% epigallocatechin, 21.3\% EGCG, 6.8\% epicatechin, $6.6 \%$ epicatechin gallate, $12 \cdot 8 \%$ gallocatechin and others) in a dose-dependent manner on renal cell viability after FK-506-induced cytotoxicity has been reported previously ${ }^{(38)}$ Moreover, the authors have shown that EGCG and epigallocatechin also reduced the cytotoxicity, whereas epicatechin and catechins had no beneficial effects ${ }^{(38)}$. Besides the results referring to EGCG specifically, several studies have indicated that the combination of polyphenols is more efficacious than a single chemically defined polyphenol ${ }^{(19,21,39)}$. Nevertheless, further studies are required to determine which component or combination of polyphenols is responsible for the beneficial effects. In hepatic I/R models, $0 \cdot 1 \%$ dietary GTE, 
Sunphenon DCF-1 (decaffeinated), containing 85\% polyphenols and $47 \cdot 2 \%$ EGCG, decreased free radical formation, TNF- $\alpha$ pro-inflammatory cytokine formation, NF- $\kappa$ B activation and liver injury ${ }^{(21)}$. However, the authors could not exclude the possibility that GTE inhibited NF- $\mathrm{B}$ activation by a non-antioxidant mechanism ${ }^{(21)}$. Because $H / R$ models an acute inflammatory condition as does hepatic I/R, the present study has been designed to test for the first time the hypothesis that $0 \cdot 1 \%$ GTE, Sunphenon 90LB, containing $>80 \%$ polyphenols and $>40 \%$ EGCG, will exert its protective, antiinflammatory effects in this model of acute inflammation and to reveal the mechanisms of protection. In support with this hypothesis, H/R-induced liver injury accompanied by enhanced serum IL-6 levels, hepatic ICAM-1 expression and neutrophil infiltration was significantly prevented by GTE administration before H/R (Figs. 1-3). Several studies have attributed liver injury to both apoptotic and necrotic cell death after $\mathrm{H} / \mathrm{R}^{(24)}$. Hepatocellular necrosis after hepatic warm $\mathrm{I} / \mathrm{R}$ occurs partly due to reactive oxygen species from activated neutrophils ${ }^{(40)}$. Reduced hepatocellular necrosis after H/R by GTE is accompanied by reduced neutrophil infiltration (Figs. 1 and 3(e)). Furthermore, protective effects of GTE are associated with reduced hepatic activation of $\mathrm{NF}-\kappa \mathrm{B}$ via the stabilisation of $\mathrm{I} \kappa \mathrm{B} \alpha$ (Fig. 4). Reduction of $\mathrm{NF}-\kappa \mathrm{B}$ activation down-regulates the expression of ICAM-1, which is accompanied by decreased neutrophil infiltration into the liver (Figs. 3 and 4). Although this down-regulation of activated NF-кB in the liver is associated with a blunted inflammatory response after $\mathrm{H} / \mathrm{R}$, the precise mechanism by which GTE treatment modulates NF- $\mathrm{BB}$ activation in the liver still remains unknown.

In conclusion, activation of NF- $\mathrm{\kappa B}$ plays an important role in the pathogenesis of liver injury after $\mathrm{H} / \mathrm{R}$ by the up-regulation of systemic IL-6, hepatic ICAM-1 expression and neutrophil infiltration. GTE reduced neutrophil infiltration, hepatic ICAM- 1 expression, IL- 6 release and liver damage by the inhibition of $\mathrm{I} \kappa \mathrm{B} \alpha$ activation. Hence, the present results suggest for the first time hepatoprotective, anti-inflammatory effects of GTE in a model of $\mathrm{H} / \mathrm{R}$ and, furthermore, the stabilisation of NF- $\mathrm{BB}$ as a potential cause for its beneficial effects.

\section{Acknowledgements}

We thank Kerstin Wilhelm and Minhong Wang for outstanding technical assistance and Heinz Schneider for providing our group with GTE. The present study was supported by Deutsche Forschungsgemeinschaft (DFG, German Research Foundation) MA 1119/3-3. The authors' contributions were as follows: B. R. was involved in the study design, experimental work, data interpretation and manuscript writing; E. T. and L. B. were involved with experimental and analytical aspects of the manuscript; H. S. provided scientific expertise on GTE; D. H. and I. M. provided scientific expertise and were involved in the study design and manuscript editing; M. L. conceptualised the study, and provided significant scientific advice and consultation throughout the study. The authors declare that they have no conflicts of interest.

\section{References}

1. Peden M \& Hyder A (2002) Road traffic injuries are a global public health problem. BMJ 324, 1153.

2. Mock C, Joshipura M, Goosen J, et al. (2006) Overview of the Essential Trauma Care Project. World J Surg 30, 919-929.

3. Baue AE, Durham R \& Faist E (1998) Systemic inflammatory response syndrome (SIRS), multiple organ dysfunction syndrome (MODS), multiple organ failure (MOF): are we winning the battle? Shock 10, 79-89.

4. Bogner V, Keil L, Kanz KG, et al. (2009) Very early posttraumatic serum alterations are significantly associated to initial massive RBC substitution, injury severity, multiple organ failure and adverse clinical outcome in multiple injured patients. Eur J Med Res 14, 284-291.

5. Moore FA, Sauaia A, Moore EE, et al. (1996) Postinjury multiple organ failure: a bimodal phenomenon. I Trauma 40, 501-510.

6. Hietbrink F, Koenderman L, Rijkers G, et al. (2006) Trauma: the role of the innate immune system. World J Emerg Surg 1, 15.

7. Partrick DA, Moore FA, Moore EE, et al. (1996) Neutrophil priming and activation in the pathogenesis of postinjury multiple organ failure. New Horiz 4, 194-210.

8. Lehnert M, Arteel GE, Smutney OM, et al. (2003) Dependence of liver injury after hemorrhage/resuscitation in mice on NADPH oxidase-derived superoxide. Shock 19, 345-351.

9. Relja B, Schwestka B, Lee VS, et al. (2009) Inhibition of c-Jun N-terminal kinase after hemorrhage but before resuscitation mitigates hepatic damage and inflammatory response in male rats. Shock 32, 509-516.

10. van Meurs M, Wulfert FM, Knol AJ, et al. (2008) Early organspecific endothelial activation during hemorrhagic shock and resuscitation. Shock 29, 291-299.

11. Meng ZH, Dyer K, Billiar TR, et al. (2001) Essential role for IL-6 in postresuscitation inflammation in hemorrhagic shock. Am J Physiol Cell Physiol 280, C343-C351.

12. Roebuck KA \& Finnegan A (1999) Regulation of intercellular adhesion molecule-1 (CD54) gene expression. J Leukoc Biol 66, 876-888.

13. Gaddipati JP, Sundar SV, Calemine J, et al. (2003) Differential regulation of cytokines and transcription factors in liver by curcumin following hemorrhage/resuscitation. Shock 19, 150-156.

14. Baeuerle PA \& Baltimore D (1989) A 65-kappaD subunit of active NF-kappaB is required for inhibition of NF-kappaB by I kappaB. Genes Dev 3, 1689-1698.

15. Hara Y (1994) Antioxidative action of tea polyphenols: part 1. Am Biotechnol Lab 12, 48.

16. Zhao BL, Li XJ, He RG, et al. (1989) Scavenging effect of extracts of green tea and natural antioxidants on active oxygen radicals. Cell Biophys 14, 175-185.

17. Frei B \& Higdon JV (2003) Antioxidant activity of tea polyphenols in vivo: evidence from animal studies. J Nutr $\mathbf{1 3 3}$, 3275S-3284S

18. Chu KO, Wang CC, Chu CY, et al. (2007) Uptake and distribution of catechins in fetal organs following in utero exposure in rats. Hum Reprod 22, 280-287.

19. Zhong Z, Connor HD, Froh M, et al. (2004) Polyphenols from Camellia sinenesis prevent primary graft failure after transplantation of ethanol-induced fatty livers from rats. Free Radic Biol Med 36, 1248-1258.

20. Fiorini RN, Donovan JL, Rodwell D, et al. (2005) Short-term administration of (-)-epigallocatechin gallate reduces hepatic steatosis and protects against warm hepatic ischemia/ reperfusion injury in steatotic mice. Liver Transpl 11, 298-308. 
21. Zhong Z, Froh M, Connor HD, et al. (2002) Prevention of hepatic ischemia-reperfusion injury by green tea extract. Am J Physiol Gastrointest Liver Physiol 283, G957-G964.

22. Tanabe N, Suzuki H, Aizawa Y, et al. (2008) Consumption of green and roasted teas and the risk of stroke incidence: results from the Tokamachi-Nakasato cohort study in Japan. Int J Epidemiol 37, 1030-1040.

23. Meng ZH, Dyer K, Billiar TR, et al. (2001) Essential role for IL-6 in postresuscitation inflammation in hemorrhagic shock. Am J Physiol Cell Physiol 280, C343-C351.

24. Lehnert M, Relja B, Sun-Young LV, et al. (2008) A peptide inhibitor of $\mathrm{C}$-jun $\mathrm{N}$-terminal kinase modulates hepatic damage and the inflammatory response after hemorrhagic shock and resuscitation. Shock 30, 159-165.

25. Kubulus D, Mathes A, Reus E, et al. (2009) Endothelin-1 contributes to hemoglobin glutamer-200-mediated hepatocellular dysfunction after hemorrhagic shock. Shock 32, 179-189.

26. Vallabhaneni $\mathrm{R}$, Kaczorowski DJ, Yaakovian MD, et al. (2010) Heme oxygenase-1 protects against hepatic hypoxia and injury from hemorrhage via regulation of cellular respiration. Shock 33, 274-281.

27. Yang S, Hu S, Chen J, et al. (2009) Mechanism of hepatoprotection in proestrus female rats following traumahemorrhage: heme oxygenase-1-derived normalization of hepatic inflammatory responses. J Leukoc Biol 85, 1015-1026.

28. Jobin C, Hellerbrand C, Licato LL, et al. (1998) Mediation by NF-kappa B of cytokine induced expression of intercellular adhesion molecule 1 (ICAM-1) in an intestinal epithelial cell line, a process blocked by proteasome inhibitors. Gut 42, 779-787.

29. Shakhov AN, Collart MA, Vassalli P, et al. (1990) Kappa B-type enhancers are involved in lipopolysaccharide-mediated transcriptional activation of the tumor necrosis factor alpha gene in primary macrophages. J Exp Med 171, 35-47.

30. Hierholzer C, Harbrecht B, Menezes JM, et al. (1998) Essential role of induced nitric oxide in the initiation of the inflammatory response after hemorrhagic shock. J Exp Med 187, 917-928.
31. Meldrum DR, Shenkar R, Sheridan BC, et al. (1997) Hemorrhage activates myocardial NFkappaB and increases TNF-alpha in the heart. J Mol Cell Cardiol 29, 2849-2854.

32. Zingarelli B, Sheehan M \& Wong HR (2003) Nuclear factorkappaB as a therapeutic target in critical care medicine. Crit Care Med 31, S105-S111.

33. Wertheimer SJ, Myers CL, Wallace RW, et al. (1992) Intercellular adhesion molecule-1 gene expression in human endothelial cells. Differential regulation by tumor necrosis factor-alpha and phorbol myristate acetate. I Biol Chem 267, 12030-12035.

34. Matsutani T, Kang SC, Miyashita M, et al. (2007) Liver cytokine production and ICAM-1 expression following bone fracture, tissue trauma, and hemorrhage in middleaged mice. Am J Physiol Gastrointest Liver Physiol 292, G268-G274.

35. Jaeschke H (1997) Cellular adhesion molecules: regulation and functional significance in the pathogenesis of liver diseases. Am J Physiol 273, G602-G611.

36. Xu H, Gonzalo JA, St Pierre Y, et al. (1994) Leukocytosis and resistance to septic shock in intercellular adhesion molecule 1-deficient mice. J Exp Med 180, 95-109.

37. Tulayakul P, Dong KS, Li JY, et al. (2007) The effect of feeding piglets with the diet containing green tea extracts or coumarin on in vitro metabolism of aflatoxin $\mathrm{B}_{1}$ by their tissues. Toxicon 50, 339-348.

38. Hisamura F, Kojima-Yuasa A, Kennedy DO, et al. (2006) Protective effect of green tea extract and tea polyphenols against FK506-induced cytotoxicity in renal cells. Basic Clin Pharmacol Toxicol 98, 192-196.

39. Guo Q, Zhao B, Li M, et al. (1996) Studies on protective mechanisms of four components of green tea polyphenols against lipid peroxidation in synaptosomes. Biochim Biophys Acta 1304, 210-222.

40. Gujral JS, Bucci TJ, Farhood A, et al. (2001) Mechanism of cell death during warm hepatic ischemia-reperfusion in rats: apoptosis or necrosis? Hepatology 33, 397-405. 